\title{
A intervenção federal na segurança pública da cidade do Rio de Janeiro à luz da Constituição Federal de 1988
}

É bastante visível, na sociedade brasileira, um aumento da criminalidade e o crescimento do crime organizado. Perceptível, também, a intenção destas organizações na criação de um poder paralelo, e para tanto, a estratégia é abalar o poder legítimo do Estado; da necessidade da manutenção da ordem, do reequilíbrio, do controle e do fortalecimento do Pacto Federativo, em que os entes buscam uma solução extrema, que nesse caso é a Intervenção Federal, na qual a União versando no polo ativo nesse processo, com o seu poder soberano retira a autonomia do Estado, de forma temporária e excepcional. O propósito é analisar a intervenção Federal, que pode se motivada por inúmeras razões, as quais são elencadas nos artigos 34 e 35 da CF/1988. A pesquisa é exploratória; a lógica, dedutiva; e a abordagem, qualitativa. Para esse, faz-se a análise dos conceitos histórico, doutrinários e constitucionais em relação ao federalismo no Estado brasileiro; os pressupostos materiais e formais da intervenção federal, a rigidez dos requisitos constitucionais em relação à intervenção federal, a possibilidade da intervenção federal de acordo com a norma constitucional vigente, e a possibilidade de intervenção federal na segurança pública. Como resultado, há de se notar quanto a eficiência de tal intervenção na Segurança Pública no estado do Rio de Janeiro, aplicada pelo Decreto no 9.288, de 16 de fevereiro de 2018 para combater tal situação desfavorável, e seu curto período de vigência, 31 de dezembro de 2018, para o restabelecimento real da ordem pública, corrigindo as mazelas e as desigualdades de décadas.

Palavras-chave: Intervenção Federal; Segurança Pública; Constituição Federal

\section{The federal intervention on the public safety of the city of Rio de Janeiro in the light of the Federal Constitution of 1988}

\begin{abstract}
It is very visible, in Brazilian Society, an increase in crime and the growth of organized crime. The organizations' intention to create a parallel power is also perceptible, and for this reason, the strategy is to shake the legitimate power of the State; of the need to maintain order, rebalance, control and strengthen the Federative Pact, in which the entities seek an extreme solution, which in this case is the Federal Intervention, in which the Union dealing with the active pole in this process, with its sovereign power withdraws the autonomy of the state in a temporary and exceptional manner. The purpose is to analyze the Federa intervention, which can be motivated by many reasons, which are listed in articles 34 and 35 of the CF / 1988. The research is exploratory; logic, deductive; and the qualitative approach. For this, the analysis of historical, doctrinal and constitutional concepts in relation to federalism in the Brazilian State is done; the material and formal assumptions of federal intervention, the rigidity of constitutional requirements in relation to federal intervention, the possibility of federal intervention in accordance with the current constitutional norm, and the possibility of federal intervention in public security. As a result, it should be noted that the effectiveness of such intervention in Public Security in the state of Rio de Janeiro, implemented by Decree No. 9,288, of February 16, 2018, to combat this unfavorable situation, and its short term, December 2018, for the real restoration of public order, correcting the ills and inequalities of decades.
\end{abstract}

Keywords: Federal Intervention; Public Security; Federal Constitution.

Topic: Direito Constitucional

Reviewed anonymously in the process of blind peer.
Received: 11/06/2018

Approved: 20/08/2018
Alexsandro da Silva

Universidade do Sul de Santa Catarina, Brasil http://lattes.cnpq.br/9142330909980362 alexsandro.silva2@unisul.br

Alexandre Fontenele da Silva

Universidade do Sul de Santa Catarina, Brasil

fontenele.alexandre@gmail.com
DOI: 10.6008/SPC2318-3039.2018.001.0001
Referencing this:

SILVA, A.; SILVA, A. F.. A intervenção federal na segurança pública da cidade do Rio de Janeiro à luz da Constituição Federal de 1988. Scientiam Juris, v.6, n.1, p.1-20, 2018. DOI: http://doi.org/10.6008/SPC2318-3039.2018.001.0001 


\section{INTRODUÇÃO}

É bastante visível, na sociedade brasileira, um aumento da criminalidade e o crescimento do crime organizado. Perceptível, também, a intenção destas organizações na criação de um poder paralelo, e para tanto, a estratégia é abalar o poder legítimo do Estado. Dentre uma das formas de atingir o Estado, escolhida por essas organizações, estão ataque as forças de segurança Pública.

Esses ataques são praticados por criminosos cada vez mais bem armados e audaciosos, utilizando-se de grande potencial ofensivo. Com isso, tentam não só abalar a estrutura do Estado, expondo a sua fragilidade, como também fazer frente às forças policiais. Com isso, verificamos um aumento nas baixas das forças de segurança. Dessa necessidade da manutenção da ordem, do reequilíbrio, do controle e do fortalecimento do pacto Federativo, os entes buscam uma solução extrema, que nesse caso é a Intervenção Federal, na qual a União, versando no polo ativo nesse processo, com o seu poder Soberano, retira a autonomia do Estado de forma temporária e excepcional.

A intervenção Federal pode ser motivada por inúmeras razões, as quais são elencadas nos artigos 34 e 35 da CF/1988. Nesse corrente ano, aconteceu um fato marcante no cenário político: pela primeira vez desde a CF de 1988, foi decretada a Intervenção Federal na Segurança Pública em um Ente Federativo, que nesse caso, foi decretado pelo Presidente da República a intervenção Federal no Estado do Rio de Janeiro. O que motivou essa medida excepcional foi pôr termo à grave comprometimento da ordem pública, ou seja, por fim a um distúrbio duradouro, visando combater um quadro de transtorno na vida social, violento, no qual o Estado não está conseguindo combater esse distúrbio de forma eficaz.

Tendo em vista a existência de outras hipóteses de intervenção federal, tanto nos Estados, quanto no Distrito Federal e nos Municípios, conforme os artigos 34 e 35 da CF/1988, foi escolhido como tema desse trabalho de conclusão de curso a hipótese elencada no inciso III, do artigo 34, na qual deslumbra a possibilidade de ser decretada pelo Presidente da República o processo interventivo com o objetivo de pôr termo a grave comprometimento da ordem pública; decisão Presidencial esta que será tomada de ofício, também conhecida como espontânea, onde serão ouvidos os Conselhos da República e da Defesa Nacional, e que será realizada de forma discricionária. Por fim, esse contexto será estudado e aprofundado nesse artigo.

\section{DISCUSSÃO TEÓRICA}

\section{Organização do Estado}

Segundo Lenza (2012), três aspectos podem ser analisados quando se fala na organização e estrutura do Estado: forma de governo, sistema de governo e forma de Estado. A forma de governo pode ser a República ou Monarquia; quanto ao sistema de governo, temos o presidencialismo ou parlamentarismo; referindo-se à forma de Estado, temos o Estado unitário ou Federação. No caso do Brasil, adotou-se a forma republicana de governo, o sistema presidencialista de governo e a forma federativa de Estado. 
De acordo com Ferreira Filho (2008), “o Estado é uma associação humana (povo), radicada em base espacial (território), que vive sob o comando de uma autoridade (poder) não sujeita a qualquer outra (soberania)". A Constituição Federal de 1988 atribuiu como sendo político-administrativa essa organização do Estado, onde os entes que integram essa federação devam conviver de forma equilibrada, sem conflitos de atribuições (BULOS, 2010).

A forma de organização do Estado que o Brasil adotou foi o Federalismo, o qual tende a preservar simultaneamente a unidade central e as autonomias dos entes (PINHO, 2011). Para Ribeiro et al. (2010), o Estado é formado por alguns elementos, e dentre esses, o povo, que é definido como sendo um conjunto de pessoas que mantém com esse Estado um vínculo jurídico, formal, político, conhecido como vínculo nacional.

Surge assim, com a Constituição Federal de 1988, uma tríplice estrutura do Estado Brasileiro, na qual estão a União acumulando um poder total, os Estados com os poderes regionais e os Municípios com os poderes locais. Esses órgãos Estatais e Municipais estão dotados de uma auto-organização, mas sempre respeitando os princípios constitucionais (FERREIRA FILHO, 1999).

\section{Federação}

O Federalismo teve sua origem nos Estados Unidos em 1787, porém em 1776 tivemos a proclamação de independência das treze colônias britânicas da América, que fez com que cada umas das colônias se tornassem um novo Estado, com soberania e com liberdade plena e independência. Com esses poderes, os Estados resolveram, através de um tratado internacional, formar a Confederação dos Estados Americanos, ou seja, foi feito um pacto de colaboração com o objetivo de proteção da antiga metrópole inglesa (LENZA, 2012).

No bojo desse pacto confederativo, era permitido a denúncia do tratado a qualquer tempo, autorizando o direito de retirada, de separação, e de secessão do pacto. Surge, então, um grande problema: a permissão do direito de secessão, que com o passar do tempo aumentava o problema das ameaças e a fragilidade diante dos iminentes ataques britânicos (LENZA, 2012).

Com isso, de acordo com Lenza (2010), buscando uma solução para essa situação, os Estados Confederados se reuniram na Filadélfia, onde se iniciaram as bases para a Federação Norte Americana. Nessa nova forma de Estado, não era permitido o direito de secessão. Cada Estado cedia parte da sua soberania para um órgão central, responsável pela unificação e centralização, sendo formado os Estados Unidos da América, e cada Estado se tornando autônomo entre si, dentro desse pacto federativo. Para Teixeira (2011),

Estado Federal, ou a forma federativa de governo, como aquela em que, num mesmo território, e sobre as mesmas pessoas, coexistem, simultânea e harmonicamente, pelo menos duas categorias de ordenamentos jurídicos - o central e os regionais - e pelo menos duas categorias de governos - o central e os regionais - cujos poderes são distribuídos e assegurados por uma Constituição rígida.

Esse modelo federativo é uma espécie de aliança, na qual os estados membros ficam com a autonomia política e cedendo a soberania para o Estado Federal (PINHO, 2011). 
De acordo com Ribeiro e Carvalho (2010), federação é a união de dois ou mais Estados, que serão conhecidos como Estados-membros. A soberania é transferida para o Estado Federal, porém os Estadosmembros continuam com a autonomia política.

Essa formação da Federação dos Estados Unidos originou-se de um movimento centrípeto, isto é, de fora para dentro, ou seja, os Estados soberanos cedem parcelas de sua soberania para um pacto federativo em um movimento de aglutinação. No caso do Brasil, a formação da Federação se deu através de um movimento centrífugo, ou melhor, de dentro para fora. (BULOS, 2010; LENZA, 2012).

Segundo Silva (2006), o federalismo que nasceu com a Constituição Norte Americana de 1787, referese a uma forma de Estado denominada Federação ou Estado Federal, tendo como característica a união de coletividades públicas dotadas de autonomia político-constitucional e autonomia federativa. Com a Proclamação da República em 1889, o Brasil assumiu a forma de Estado Federal, sendo mantida nas constituições seguintes. A federação consiste na união de coletividades regionais autônomas, chamada de Estados federados.

\section{Estado Federal Brasileiro}

Segundo Branco (2012), é muito importante que cada país atente para suas necessidades e que venha escolher a forma federativa do Estado que mais se encaixe ao seu Estado, que no caso do Brasil adotou a União como sendo o fruto dessa ligação dos Estados entre si. Em outras palavras, essa união é indissolúvel. A federação se objetiva em distribuir o poder, preservando a autonomia dos entes políticos que a compõem; autonomia essa que não é ilimitada ou incondicionada de atuação no ordenamento jurídico, mas sim a disponibilidade de algumas matérias, sempre respeitando a Constituição Federal (BASTOS, 2000; FERREIRA FILHO, 2008).

Nesse sentido, Bulos (2010) afirma que essa autonomia dos entes federados vem acompanhada de alguns atributos, sendo eles: a auto-organização; a autolegislação; a autoadministração; e o autogoverno.

A União no plano legislativo, edita leis federais que abrangem os servidores federais, o aparato administrativo federal, e editam leis nacionais que abrangem todos os habitantes do território nacional e em outras esferas da federação (BRANCO,2012).

Segundo Silva (2006), os componentes do Estado federal, de acordo com o artigo $1^{\circ}$ da Constituição Federal, são a União, os Estados, os Municípios e o Distrito Federal, sendo um laço indissolúvel. Para manter esse equilíbrio na relação dos entes federados, a constituição veio adotar um sistema complexo por meio da repartição de competências, que vêm fundamentado na enumeração dos poderes da União, e que se encontra nos artigos 21 e 22; com poderes remanescentes para os Estados, que está elencados no caput do artigo 25 e em seu parágrafo primeiro; e com poderes definidos para os Municípios, no artigo 30. Quando se tratar de áreas comuns onde são previstas atuações paralelas dos entes federados, esses estão elencados no artigo 23. Todos esses artigos mencionados são da Constituição federal.

Destaca o princípio federativo, que está mencionado no artigo $1^{\circ}$ da $\mathrm{CF}$, no qual a forma de governo federativo é responsável pela indissolubilidade de seus entes (princípio da indissolubilidade), não existindo 
assim o direito de secessão. Qualquer ato que atente a essa harmonia, pacífica e cooperativa entre os entes será feito o uso da intervenção federal (BULOS, 2010; MORAES, 2017).

De acordo com Branco (2012), a forma federativa do Estado é cláusula pétrea, ou seja, não é passível de deliberação à proposta de emenda que venha modificar o Estado Federal. Essa previsão consta no texto constitucional do artigo 60, parágrafo quarto, inciso I:

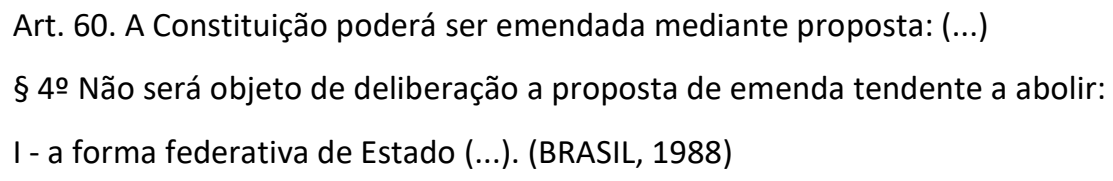

\section{Intervenção Federal}

Para Bastos (2000), a intervenção federal é uma medida de interesse nacional, pois quando a União intervém em um determinado Estado, na verdade todos os entes da federação estão intervindo juntos, ou seja, o Congresso Nacional irá apreciar a matéria em alguns casos. O Congresso Nacional, sendo composto por Senadores, que expressam a vontade dos Estados membros e os Deputados Federais, que representam a vontade do povo.

A intervenção federal é uma medida de caráter excepcional de defesa estatal, na qual é retirada temporariamente a autonomia do ente federativo que sofrerá essa medida, prevalecendo a vontade da União. As hipóteses previstas para intervenção estão previstas taxativamente na Constituição Federal, sendo que a regra é a não-intervenção (BASTOS, 2000; BERNARDES et al., 2018).

Três pontos são importantes para a manutenção do equilíbrio do Estado Federal: o primeiro é o princípio da não-intervenção, na qual essa medida interventiva somente poderá ser decretada no caso de extrema necessidade; o segundo é o princípio da temporariedade, pois o prazo de duração da intervenção tem que ser respeitado, não podendo ser ultrapassado; e por último, temos o princípio da proporcionalidade, na qual todo ato estatal é condicionado (BERNARDES et al., 2018).

A autonomia de um ente estatal significa que esse ente é capaz de agir dentro do seu limite estabelecido anteriormente e que a intervenção é totalmente o inverso dessa autonomia, ou seja, um ente federativo antes autônomo com a intervenção irá perder essa autonomia temporariamente (PINHO, 2011). A intervenção federal é uma medida temporária e excepcional, com hipóteses restritas contidas nas Constituição Federal, que autoriza que um ente federado passe a ter o controle nos negócios políticos de outra entidade federada, retirando-Ihe, por tempo determinado, essa autonomia (CUNHA JÚNIOR et al., 2015; MASSON, 2015).

A intervenção é um ato temporário. Essa duração fica estabelecida no decreto. Quando cessarem os motivos da intervenção, as autoridades que foram afastadas de seus cargos irão retornar, salvo se por algum motivo tiverem um impedimento previsto em lei. Lembramos que esse afastamento das autoridades visa permitir o retorno da normalidade constitucional (PINHO, 2011; SILVA, 2006). 
A figura do interventor é constitucional e suas funções limitadas ao ato de intervenção são federais, que ao executar atos e tomar decisões que prejudiquem terceiros, esse prejuízo causado é de responsabilidade civil da União (SILVA, 2006).

Segundo Bernardes e Ferreira (2018), a intervenção federal acarreta no afastamento temporário da autonomia do ente federativo que sofre essa medida extrema, vindo a prevalecer a autonomia do ente interventor. Esse processo interventivo não tem como objetivo a punição dos agentes políticos das entidades sofredoras desse ato, e busca o equilíbrio, ou que seja mantida essa integridade do Estado Federal. Outro ponto importante é que nesse prazo da incidência da intervenção federal, o processo de reforma constitucional ficará suspenso, vide artigo 60, parágrafo 1 da Constituição Federal:

Art.60 (...)

$\S 1$ 10 A Constituição não poderá ser emendada na vigência de intervenção federal, de estado de defesa ou de estado de sítio.

Como destaca Bulos, (2010), "Intervenção é a cessação excepcional da autonomia política dos Estados, Distrito Federal ou Municípios, com vistas ao restabelecimento do equilíbrio federativo". Para Paulo e Alexandrino (2008), a intervenção é descrita de forma taxativa no texto constitucional, tratando-se de uma medida de caráter excepcional, sendo exceção ao princípio da não-intervenção. A decretação da intervenção é um ato político, exclusivo do Presidente da República no caso da União, ou do Governador, no caso dos Estados.

A intervenção pode ser efetivada de duas maneiras: de forma espontânea ou provocada. No caso da espontânea, podendo ser chamada de ofício, ela é autorizada por iniciativa própria pelo chefe do Poder Executivo, que fará um juízo de discricionariedade, decidindo de ofício o plano executor da intervenção após ouvir o Conselho da República e o Conselho da Defesa Nacional. Previstas na constituição as três hipóteses da intervenção espontânea, tem-se: para defender a unidade nacional, encontrada no artigo 34, incisos I e II da CF; defender a ordem pública, artigo 34, inciso III da CF; e para defender as finanças públicas, artigo 34, inciso V da CF (PAULO et al., 2008; MOTTA et al., 2009).

A outra maneira é a intervenção federal provocada, que neste caso, depende da provocação de um órgão competente. Essa provocação poderá ser mediante solicitação ou requisição. A requisição é imperativa. O chefe do Poder Executivo não fará o juízo de discricionariedade, sendo obrigado a decretar; no caso da solicitação, não há essa obrigação (PAULO et al., 2008; MOTTA et al., 2009).

De acordo com Lenza (2012), existem quatro espécies de intervenção federal: a primeira é a espontânea, na qual o Presidente da República age de ofício; a segunda é a provocada por solicitação quando o impedimento recair sobre os Poderes e Executivo e Legislativo nas suas atribuições que a decretação da intervenção pelo Presidente da República dependerá de solicitação dos poderes impedidos; a terceira é a provocada por requisição. Em caso de a coação ser feita contra o Poder judiciário, a decretação da intervenção dependerá de requisição do Supremo Tribunal Federal; e a provocada que depende de provimento de representação, quando ocorre ofensa aos princípios constitucionais sensíveis à intervenção, 
que dependerá de provimento pelo Supremo e de representação do Procurador Geral da República. Observam-se quatro fases procedimentais da intervenção federal, segundo Motta et al. (2009) sendo elas:

(i) iniciativa, tem relação com as modalidades de intervenção;

(ii) judicial, para prover a execução de lei federal ordem ou decisão judicial e para assegurar a observância dos princípios constitucionais sensíveis;

(iii) edição do decreto;

(iv) controle político do poder legislativo.

A provocada pode ser requisitada pelo Supremo Tribunal Federal, Superior Tribunal de Justiça ou pelo Tribunal Superior Eleitoral. O Presidente da República age de modo vinculado, devendo decretar o ato de intervenção, salvo se for o caso de suspensão da execução do ato. Por representação, o Procurador-Geral da República formulará uma representação ao Supremo Tribunal Federal pleiteando pela intervenção, podendo também, através de uma ação direta de constitucionalidade para o mesmo Tribunal, solicitando que seja assegurada os princípios chamados sensíveis (BULOS, 2010).

As hipóteses descritas de forma taxativa no artigo 34 da Constituição Federal, são as hipóteses nas quais a União intervirá nos Estados (MOTTA et al., 2009). De acordo com Branco (2012), a intervenção federal é um mecanismo drástico e excepcional, que se destina na manutenção da integridade dos princípios basilares elencados no artigo 34 da Constituição Federal. É de responsabilidade da União a preservação da integridade política, jurídica e física de uma federação. Em sua obra, Pinho (2011) propõe as hipóteses da intervenção federal que estão descritas no artigo 34 da Constituição Federal, totalizando 07 (sete) possibilidades. São elas:

No caso dos incisos I e II, tratam da defesa estatal, onde o objetivo é a manutenção da integridade nacional e o combate a invasão estrangeira;

No caso dos incisos II, III e IV, tratam da defesa da Federação, nos quais se busca evitar que uma unidade federativa invada outra; no caso de a ordem pública estar gravemente comprometida; por fim, da garantia de que as atividades dos poderes das unidades sejam realizadas livremente;

No caso do inciso $V$, tem relação com as finanças, tendo em vista que os entes precisam se manter com verbas próprias e com as repassadas por direito nos prazos determinados pela lei. O objetivo principal é a reorganização financeira; e

No caso dos incisos VI e VII, têm relação com a defesa da ordem constitucional, fato que seja garantida a execução da lei federal, assegurando que os princípios constitucionais sensíveis não sejam violados.

\section{Pressupostos}

Conforme Lenza (2012), a intervenção se materializará por meio de um decreto presidencial de intervenção que mencionará a prazo as condições de execução, especificará a sua amplitude, e quando couber, nomeará um interventor. Essa competência é privativa do Presidente da República, quando a decretação for de forma espontânea ou provocada. O controle político será feito pelo Congresso Nacional sobre o decreto de intervenção expedido pelo Presidente da República no prazo de vinte e quatro horas. Porém, se a casa legislativa estiver em recesso, será convocada uma assembleia extraordinária também no 
prazo de vinte quatro horas para apreciar a matéria. Caso o Congresso rejeite o decreto interventivo, o Presidente da República deverá cessar imediatamente, sob o risco de responder criminalmente.

Os pressupostos materiais da intervenção são encontrados de forma taxativa no artigo 34 da Constituição Federal, dos incisos I até o VII. Destacamos a manutenção da integridade nacional, já que no Brasil é proibido o direito a secessão; logo, o Presidente da República irá agir de ofício, de forma discricionária, exercendo assim o comando das Forças Armadas e realizando as nomeações para os cargos que Ihes são privativos. Em caso contrário, incidirá no crime de responsabilidade (BASTOS, 2000; BULOS, 2010).

Com relação ao combate de uma invasão estrangeira, o Presidente da República irá intervir, pois trata-se de uma afronta ao Estado Federal em sentido macro, cabendo ao Comandante Supremo das Forças Armadas, em conjunto com o chefe do Poder Executivo, defender o território nacional contra os invasores estrangeiros (BULOS, 2010). No caso de uma invasão de uma unidade federativa em outra, o processo de intervenção vai atuar no sentido de cessar essa agressão, tanto no ente invasor, quanto no invadido (BULOS, 2010).

Quando os atos comprometem a paz e a legalidade, a qual os cidadãos descumprem o preceito legal sem constrangimento, afrontando assim, o poder exercido pelas autoridades, a intervenção se faz necessária, a exemplo do caso da garantia do livre exercício dos três poderes, que no caso do Legislativo ou Executivo sendo ameaçado ou coagido, o Presidente da República fica atrelado a uma deliberação; já o Judiciário, com a requisição do Supremo Tribunal federal (BULOS, 2010).

Sempre que o assunto for a reorganização das finanças da unidade da federação, também é mais um caso que autoriza o processo interventivo, junto à execução da lei Federal e quando esse conflito não puder o Judiciário solucionar essa lide (BULOS, 2010). Como forma de garantia dos princípios constitucionais sensíveis a intervenção, faz-se presente como um dos requisitos materiais do artigo 34 da CF (BULOS, 2010). Em sua obra, Bulos (2010) destaca que os pressupostos formais estão elencados no artigo 36, incisos I, II, III da CF:

\footnotetext{
Art. 36. A decretação da intervenção dependerá:

I - no caso do art. 34, IV, de solicitação do Poder Legislativo ou do Poder Executivo coacto ou impedido, ou de requisição do Supremo Tribunal Federal, se a coação for exercida contra o Poder Judiciário;

II - no caso de desobediência a ordem ou decisão judiciária, de requisição do Supremo Tribunal Federal, do Superior Tribunal de Justiça ou do Tribunal Superior Eleitoral;

III - de provimento, pelo Supremo Tribunal Federal, de representação do Procurador-Geral da República, na hipótese do art. 34, VII, e no caso de recusa à execução de lei federal. (Redação dada pela Emenda Constitucional no 45, de 2004)
}

De acordo com Silva (2006), a intervenção federal possui seus pressupostos formais, tais como o modo de sua efetivação, seus limites e requisitos. Essa intervenção é efetivada com o decreto do Presidente da República, que especificará a amplitude, o prazo, as condições de execução, e se couber, nomeará um interventor. $\mathrm{O}$ decreto de intervenção dependerá da simples verificação dos motivos que a autorizam, sendo 
isso verificado nos casos dos incisos I, II, III e V do artigo 34 da CF. Já no caso do inciso IV, da solicitação do Poder Legislativo ou do Executivo, ou também da requisição do Supremo Tribunal Federal se a coação for contra o Poder Judiciário. Agora no caso do inciso VI, verifica-se que há uma requisição do Supremo Tribunal Federal, do Superior Tribunal de Justiça ou do Tribunal Superior Eleitoral nos casos de desobediência à decisão judicial. O caso do inciso VII, de provimento do Supremo Tribunal Federal, é de representação do Procurador-Geral da República (SILVA, 2006).

Para Paulo et al. (2006), a intervenção federal terá sua eficácia imediata a partir do decreto interventivo expedido pelo Presidente da República, que legitimará os outros chefes do Poder Executivo na execução dessa medida. Nesse decreto o Presidente da República mencionará a amplitude, o prazo, as condições, a nomeação do interventor, o afastamento das autoridades locais das funções. Logo, se a intervenção atingir o Poder Executivo, o Presidente da República irá nomear um interventor, para que ele exerça as funções do governador.

Para Masson (2015), a intervenção será decretada pelo Presidente da República. Após as oitivas dos conselheiros da República e da Defesa Nacional, esses pareceres não são vinculantes; apenas opinativos. $O$ Presidente fará por meio de um decreto a intervenção, tendo como pressupostos materiais são encontrados taxativamente, nas hipóteses do artigo 34 da Constituição Federal.

Os pressupostos formais têm relação com os procedimentos, sendo eles: nos incisos I, II, III e V do artigo 34 da Constituição federal, a intervenção será espontânea, isto é, o Presidente da República decretará de ofício. Temos também a intervenção provocada por solicitação (um pedido) e a provocada por requisição (uma ordem). No caso da intervenção provocada por solicitação, encontramos com as leituras do artigo 36, inciso I primeira parte com o artigo 34, inciso IV, ambos da Constituição Federal, temos as hipóteses dos membros dos Poderes legislativos e Executivos Estaduais sofrerem coações ou serem impedidas de atuarem livremente no exercício que Ihes são atribuídos. Nesse caso, o chefe do poder local fará uma solicitação ao Presidente da República, para que seja analisado o pedido de intervenção (MASSON, 2015).

\section{Finalidade e competência}

A intervenção federal tem como finalidade a defesa do Estado, a defesa do princípio federativo, a defesa das finanças estaduais e a defesa da ordem constitucional. Esse decreto de intervenção federal será submetido ao chefe do poder executivo que será apreciado pelo Congresso Nacional num prazo de vinte e quatro horas, que poderá ser aprovado ou rejeitado podendo até ser suspenso. No caso de suspender a intervenção, a mesma passara a ser ato inconstitucional, devendo ser cessada imediatamente, que se for mantida será caracterizada como crime de responsabilidade do Presidente da República, ficando o chefe do executivo sujeito a processo e sanções (SILVA, 2006).

Para Pinho (2011), a intervenção federal tem como finalidade a manutenção do equilíbrio federal. De acordo com Paulo et al. (2006) destaca os órgãos que iniciaram a intervenção, sendo eles: 
locais farão uma solicitação ao Presidente da República, com a finalidade de que seja garantida essa liberdade de exercício das funções. Exemplo prático: Se o Governador do Rio de Janeiro estivesse sendo coagido ou ameaçado no exercício das suas atribuições, o Presidente da República não poderia de ofício decretar a intervenção; teria que ser provocado pelo Governador do Rio de Janeiro através de uma solicitação direcionada para o Presidente de República, que analisará sem o viés da obrigação da decretação dessa medida de exceção;

STF: caso o poder judiciário local estiver sendo coagido, cabe ao Tribunal de Justiça Local provocar o Supremo Tribunal Federal, que se concordar, requisitará a intervenção do Presidente da República. Observamos que o Poder Judiciário local não tem competência para provocar de forma direta o Presidente da República, diferente dos demais poderes Executivo e Legislativo. Esse instituto da requisição obriga o Presidente da República a decretar a intervenção;

STF, STJ ou TSE (no caso do artigo 34, inciso VI da CF): Essa intervenção dependerá de requisição de um desses tribunais direcionado para o Presidente da República, dependendo da origem da decisão descumprida;

Procurador-Geral da República: no caso de ofensas aos princípios sensíveis e de recusa na execução da lei federal. Neste sentido, o Procurador irá fazer uma representação de intervenção para o STF. Importante mencionar que o Supremo não decretará a intervenção, pois essa é função exclusiva do Presidente da República; cabe ao Supremo fazer o controle de constitucionalidade da medida de autonomia de ente. Caso o Supremo receba a representação, fará a provocação ao Presidente da República, para que seja expedido o decreto interventivo, que nesse caso a atuação do Presidente é vinculada, cabendo a ele fazer a formalização dessa decisão tomada pelo poder judiciário.

Quando a intervenção for provocada pelo STJ ou pelo TSE, poderão requisitar diretamente para o Presidente da República, quando a ordem descumprida for própria. No caso do STF irá requisitar ao Presidente da República nas seguintes hipóteses, quando houver descumprimento de ordem ou decisões judiciais, para que sejam cumpridas decisões da Justiça Estadual, Federal, Trabalhista ou Militar. É bom destacar que no caso da Justiça Estadual, somente o Tribunal local possui legitimidade para encaminhar ao STF o pedido de intervenção, tendo como justificativa o não-cumprimento de suas decisões (MORAES, 2017).

Já o Procurador-Geral da República, a fim de que a lei federal seja cumprida, irá encaminhar ao Supremo uma Ação de Executoriedade da Lei Federal. No caso de garantia da forma república, do regime democrático e dos direitos da pessoa humana, o Procurador irá encaminhar uma Ação direita de inconstitucionalidade interventiva para o Supremo, tendo em vista que essas hipóteses de legitimidade do Procurador-Geral da República se encontram nos incisos VI (parte inicial) e VII do artigo 34 da CF (MORAES, 2017).

Um ponto de grande importância é a figura do interventor, que é a autoridade nomeada pelo Presidente da República para resolver a questão pela qual se justificou a retirada da autonomia do ente federativo. O interventor é uma autoridade federal na qual sua função fica limitada ao ato de intervenção (PINHO, 2011).

De acordo com Ferreira Filho (1999), o Presidente da República é competente para a decretação da intervenção federal, podendo ser vinculada ou discricionária. Sempre que a intervenção vier de uma decisão do Poder Judiciário mediante requisição, o Presidente da República irá apenas formalizar essa ato, como o chamado decreto interventivo; já no caso da decisão discricionária do Presidente da República, quando se propuserem as hipóteses de ameaça à integridade nacional, no caso de invasão estrangeira; de um Estado 
invadir outro; de perturbação grave da ordem, os Poderes Legislativos e Executivos Estaduais estarem sendo coagidos; ou para reorganizar as finanças dos Estados membros.

Bulos (2010) menciona que a intervenção federal possui quatro fases: a inicial, a judicial, a decretação da intervenção e do controle político judicial. Na primeira fase, destacam-se os legitimados para dar início no processo interventivo, sendo eles: Presidente da República ( Incisos I, II, III e V da CF); Poderes Públicos Locais (Inciso IV, da CF); STF, STJ, e TSE (Inciso VI, segunda parte, da CF); e o Procurador-Geral da República (inciso VI e VII da CF).

Descreve-se que na fase judicial incide nos incisos VI e VII do artigo 34, da CF. Na fase do decreto, uma vez publicado, seus efeitos são imediatos, tendo o Presidente da República essa missão exclusiva indelegável. No decreto irá constar a amplitude, o prazo, as condições de execução, nomeação ou ao do interventor, como também o momento de cessar os efeitos da intervenção (BULOS, 2010).

Já que a intervenção é um ato político, temporário e de caráter excepcional, cabendo ao Congresso Nacional (nos incisos VI, VII do artigo 34 e inciso IV do artigo 35 ambos da CF), por intermédios dos senadores e deputados exercer esse controle político do decreto, dentro de um prazo de vinte e quatro horas, podendo ser aprovado ou rejeitado pelos integrantes do Poder Legislativo Federal por meio de um decreto, no controle Judiciário, é função do STF quando houver os atos praticados pelo interventor atentar contra a CF (BULOS, 2010).

Para Masson (2015), é de competência exclusiva do Presidente da República a decretação da intervenção, vide artigo 84, inciso X, da Constituição Federal. Nesse decreto conterá a amplitude da intervenção; o prazo; as condições da execução; a indicação de interventor. O Presidente da República irá nomear um interventor federal, se achar imprescindível para a intervenção, já que o interventor irá executar essa medida extraordinária e substituir as autoridades locais detentoras das atribuições que serão abrangidas pela intervenção. $O$ interventor irá praticar os atos de império, os quais são decorrentes da delegação do cargo de interventor, ou seja, será uma autoridade federal, representante da União. Outro ato praticado é de gestão, o qual o interventor irá executar, são as atividades para a manutenção da Administração Estadual (MASSON, 2015). Correlaciona Bastos (2000) que a efetivação do ato interventivo ocorre sempre por um decreto Presidencial, no qual o Presidente da República ouvirá conselho da República, que ditará a amplitude, o prazo, as condições de execução, a nomeação de interventor.

\section{Controle político}

Nesse sentido, Bastos (2000) afirma que o decreto Presidencial passará pelo Congresso Nacional, que num prazo de vinte e quatro horas apreciará essa matéria excepcional. Caso a casa legislativa esteja de recesso, será convocada uma sessão extraordinária para avaliar esse tema.

As hipóteses que o Congresso Nacional apreciará são elencadas nos incisos, I, II, III e V do artigo 34 da CF, ou seja, a manutenção da integridade nacional; combater invasão estrangeira ou de uma unidade federativa em outra; pôr termo a grave comprometimento da ordem pública e a reorganização das finanças das unidades federais (BASTOS, 2000). 
Nas hipóteses de cabimento de controle político, o decreto de intervenção do Presidente da República deverá ser submetido à apreciação do Congresso Nacional no prazo de 24 horas. [...]. O controle político exercido pelo Congresso Nacional é dispensado apenas nos casos em que a intervenção for decretada para prover a execução de lei federal, ordem ou decisão judicial ou para assegurar a observância dos princípios constitucionais sensíveis. (NOVELINO, 2017)

Esse decreto interventivo deverá ser submetido à apreciação do Congresso Nacional no prazo estipulado de 24 (vinte e quatro) horas. Caso a casa legislativa estiver em recesso, haverá uma convocação extraordinária num prazo de 24 (vinte e quatro) horas. As medidas interventivas já foram iniciadas com o decreto, o Presidente da República declara a intervenção, não solicita autorização para o Congresso Nacional e sim a apreciação da matéria (PAULO et al., 2006).

O Congresso Nacional pode aprovar ou determinar a suspensão, vide artigo 49, inciso IV da CF. Com a aprovação é expedido um decreto legislativo; caso não aprove a intervenção passará a ser ato inconstitucional, e com isso deverá parar imediatamente, pois se mantida, o Presidente da República responderá criminalmente, já que estará atentando contra a autonomia do ente federado (PAULO et al., 2006).

O controle político será exercido pelo Congresso Nacional no prazo de 24 (vinte e quatro) horas e caso a casa legislativa esteja em recesso será convocada uma sessão extraordinária para apreciar a matéria também pelo prazo de 24 (vinte e quatro) horas (SANTOS, 2016).

O controle político deve ser realizado pelos que representam o povo, sendo a Câmara dos Deputados e dos Estados-membros que no caso é o Senado Federal, com o objetivo de garantir a excepcionalidade da medida. Em um prazo de 24 (vinte e quatro) horas para apreciação, devendo ser aprovado ou rejeitado, através de decretos. Entretanto, se a intervenção for rejeitada, o Chefe do Poder Executivo cessará imediatamente o processo interventivo, ou caso não o faça, responderá por crime de responsabilidade, vide artigo 85, II da CF (MORAES, 2017).

Em sua obra, Moraes (2017) reitera que a CF, com a redação do artigo 36, parágrafo 3, dispensou o controle político nas hipóteses dos incisos VI e VII de seu artigo 34, conforme previsto na CF:

Art. 34. (...)

V - reorganizar as finanças da unidade da Federação que:

a) suspender o pagamento da dívida fundada por mais de dois anos consecutivos, salvo motivo de força maior;

b) deixar de entregar aos Municípios receitas tributárias fixadas nesta Constituição, dentro dos prazos estabelecidos em lei; (...)

VII - assegurar a observância dos seguintes princípios constitucionais:

a) forma republicana, sistema representativo e regime democrático;

b) direitos da pessoa humana;

c) autonomia municipal;

d) prestação de contas da administração pública, direta e indireta.

e) aplicação do mínimo exigido da receita resultante de impostos estaduais, compreendida a proveniente de transferências, na manutenção e desenvolvimento do ensino e nas ações 
e serviços públicos de saúde. (Redação dada pela Emenda Constitucional no 29, de 2000) (BRASIL, 1988).

O controle político será feito pelo Congresso Nacional, em um prazo de 24 (vinte e quatro) horas, contadas a partir da comunicação da intervenção, através de um decreto expedido pelo Presidente da República. Em caso de recesso legislativo, os parlamentares serão convocados extraordinariamente para apreciar a matéria em 24 (vinte e quatro) horas. Sendo aprovada pela maioria simples dos congressistas, a intervenção poderá continuar ou poderá ser suspensa. No caso da suspensão ou rejeição, o Presidente da República cessará imediatamente a intervenção sob pena de responder pelo crime de responsabilidade, vide artigo 85, II da CF (BERNARDES et al., 2018; MASSON, 2015; PINHO, 2011).

Art. 85. São crimes de responsabilidade os atos do Presidente da República que atentem contra a Constituição Federal e, especialmente, contra: [...]

II - o livre exercício do Poder Legislativo, do Poder Judiciário, do Ministério Público e dos Poderes constitucionais das unidades da Federação. (BRASIL, 1988)

Esse controle político não irá ocorrer quando a intervenção for de requisição judicial. A única exceção é no caso do STF, que garantirá o livre exercício do Poder Judiciário local (BERNARDES et al., 2018). Não cabe controle político quando a intervenção federal é decretada nos seguintes casos: para execução de lei federal, decisão ou ordem judicial e para proteção dos princípios constitucionais sensíveis, tendo em vista que os pressupostos materiais da intervenção estarão sendo avaliados pelo Tribunal do Poder Judiciário que terá feito a requisição ao Presidente da República (MASSON, 2015).

De acordo com Ferreira Filho (2008), a intervenção deve ser analisada pelo Congresso Federal, exceto quando a intervenção tiver origem de uma requisição do Poder Judiciário. Caso a casa legislativa federal não aprove a intervenção, a medida será imediatamente suspensa, tendo seus efeitos ex nunc. Com o fim da intervenção, as autoridades estaduais que foram substituídas voltarão aos seus postos, exceto se tiver algum impedimento.

\section{Intervenção nos municípios}

Conforme Paulo et al. (2006), os Estados-membros podem intervir nos Municípios localizados em seu território, através de um decreto expedido pelo Governador. Já no caso de um Município localizado em um território federal, a capacidade ativa legal é da União, que se dará através de um decreto do Presidente da República. Constam no artigo 35 da Constituição Federal as hipóteses que autorizam essa intervenção estatal.

Em sua obra, Bernardes et al. (2018) explicam os motivos que levam a uma intervenção Municipal, e esses estão expressos de forma taxativa no artigo 35 da Constituição Federal, não podendo ser alterados pelas Constituições Estaduais. Os fatores que permitem essa intervenção são relacionados em grande parte com tributos, receitas e finanças.

Art. 35. O Estado não intervirá em seus Municípios, nem a União nos Municípios localizados em Território Federal, exceto quando:

I - deixar de ser paga, sem motivo de força maior, por dois anos consecutivos, a dívida fundada;

II - não forem prestadas contas devidas, na forma da lei; 
III - não tiver sido aplicado o mínimo exigido da receita municipal na manutenção e desenvolvimento do ensino e nas ações e serviços públicos de saúde; (Redação dada pela Emenda Constitucional no 29, de 2000)

IV - o Tribunal de Justiça der provimento a representação para assegurar a observância de princípios indicados na Constituição Estadual, ou para prover a execução de lei, de ordem ou de decisão judicial.

Art. 36. A decretação da intervenção dependerá:

I - no caso do art. 34, IV, de solicitação do Poder Legislativo ou do Poder Executivo coacto ou impedido, ou de requisição do Supremo Tribunal Federal, se a coação for exercida contra o Poder Judiciário;

II - no caso de desobediência à ordem ou decisão judiciária, de requisição do Supremo Tribunal Federal, do Superior Tribunal de Justiça ou do Tribunal Superior Eleitoral;

III - de provimento, pelo Supremo Tribunal Federal, de representação do Procurador-Geral da República, na hipótese do art. 34, VII, e no caso de recusa à execução de lei federal. (Redação dada pela Emenda Constitucional no 45, de 2004)

IV - (Revogado pela Emenda Constitucional no 45, de 2004)

$\S 1$ 응 0 decreto de intervenção, que especificará a amplitude, o prazo e as condições de execução e que, se couber, nomeará o interventor, será submetido à apreciação do Congresso Nacional ou da Assembléia Legislativa do Estado, no prazo de vinte e quatro horas.

§ 2ㅇ Se não estiver funcionando o Congresso Nacional ou a Assembléia Legislativa, far-se-á convocação extraordinária, no mesmo prazo de vinte e quatro horas.

$\S 3$ ㅇ Nos casos do art. 34, VI e VII, ou do art. 35, IV, dispensada a apreciação pelo Congresso Nacional ou pela Assembléia Legislativa, o decreto limitar-se-á a suspender a execução do ato impugnado, se essa medida bastar ao restabelecimento da normalidade.

$\S 4$ ㅇ Cessados os motivos da intervenção, as autoridades afastadas de seus cargos a estes voltarão, salvo impedimento legal.

\section{Cooperação entre os entes federados e a Força Nacional de Segurança Pública}

Segundo Lenza (2016), essa matéria está disciplinada na Lei 11.473 de 2007, na qual consta que a União poderá realizar acordos ou convênios com os Estados-membros e o Distrito Federal, para que sejam executadas atividades e serviços indispensáveis à preservação da ordem pública e da incolumidade das pessoas e patrimônios. Esse acordo visa diminuir os efeitos que geram danos a população.

Em 2004, através do decreto 5.289, que disciplina o funcionamento da Administração Pública Federal, no qual foi criado um programa de cooperação federativa denominado Força Nacional de Segurança Pública, essa cooperação federativa tem que ser de forma consensual com a coordenação dos entes envolvidos nesse pacto. Existem formalidades, que nesse caso da cooperação federativa, o governador do Estado-membro, do Distrito Federal ou do Ministro do Estado, mediante solicitação expressa para a União, nas quais com esse apoio da Força Nacional, atuará exclusivamente nas atividades de policiamento ostensivo, sempre destinados à preservação da ordem pública e da incolumidade das pessoas e patrimônios. A criação da Força Nacional de Segurança Pública pelo governo federal tem como objetivo apoiar os Estados Membros e o Distrito Federal em momentos de crise (LENZA, 2016). 


\section{Da segurança pública}

Conforme Silva (2006) diz, "segurança" que significa garantia, proteção, estabilidade e dando continuidade às definições, vem a "segurança jurídica", que consiste na certeza do negócio jurídico. A "ordem pública" é uma situação de convivência em sociedade de forma pacífica, sem ameaças violentas, podendo ter divergências de opiniões. Já "segurança pública" significa a preservação ou reestabelecimento da convivência em sociedade, permitindo que todos usufruam de seus direitos e exerçam suas atividades sem perturbar os outros. Numa visão mais técnica, segurança pública é uma atividade de vigilância, preservação e combate às condutas criminosas, conforme menciona o artigo 144 da Constituição Federal de 1988.

Na visão de Bulos (2010), "Segurança pública é a manutenção da ordem pública interna do Estado". De acordo com Bulos (2010), a segurança pública tem como finalidade a manutenção da paz, sendo este um dever estatal, sendo exercida pela polícia, que tem a função de evitar a transgressão da ordem jurídica, com o intuito de preservar a ordem pública e a incolumidade das pessoas e coisas.

A segurança pública tem alguns objetivos basilares, sendo o da preservação da ordem pública e da incolumidade das pessoas e patrimônios. Destacamos que todos estamos envolvidos com a segurança pública sendo ela dever do Estado e direito com a responsabilidade de todos (LENZA, 2016). As unidades de polícia pacificadora que foram criados no Estado do Rio de Janeiro, tiveram suas implantações em 2008, com o objetivo da retomada de territórios que são controlados pelos criminosos e o reestabelecimento da paz (LENZA, 2016).

A segurança pública é exercida pelas polícias federal, rodoviária federal, ferroviária federal, civil, militar e corpo de bombeiros militares, que dentro da constituição federal existe uma repartição de competências entre a União e o Estado, ou seja, cada unidade da federação se responsabiliza pela segurança pública, sendo assim cada vez mais fortalecido o princípio federativo. Cabe aos Estados organizar a segurança pública, e caso não o façam devidamente, poderá haver ocasião de intervenção federal, vide artigo 34, inciso III da constituição federal (SILVA, 2006).

Na obra de Bernardes et al. (2018), temos o gênero chamado de polícia de segurança com suas espécies: a polícia ostensiva e a polícia judiciária, na qual a ostensiva, a exemplo da Polícia Militar, tem a função de executar medidas preventivas, visando a preservação da ordem pública; a judiciária, a exemplo da Polícia Civil, tem a função primária de investigar os delitos penais e apurar as autorias, fazendo com que o titular da ação penal tenha elementos para que possa ajuizar a ação. Afirma Silva (2008) que

Quando a Constituição atribui às Polícias Federais a competência na matéria, logo se vê que são atribuições em campo e questões delimitados e estritamente enumerados, de maneira que, afastadas essas áreas especificadas, a segurança pública é de competência da organização dos Estados [...]. Cabe, pois, aos Estados organizar a segurança pública. Tanto é de sua responsabilidade primária o exercício dessa atividade que, se não cumprir devidamente, poderá haver ensejo de intervenção federal, nos termos do art. 34, III, que dá como um dos objetivos da intervenção federal, "pôr termo a grave comprometimento da ordem pública". 


\section{Intervenção federal na segurança pública}

Para Ferreira Filho (2008), a decretação da intervenção federal é de competência do Presidente da República, vide artigo 84, inciso X da Constituição Federal, que na hipótese do artigo 34, inciso III da Constituição, é um ato discricionário. Nessa hipótese, o Estado está sofrendo perturbação grave da ordem, ou seja, está correndo sério risco de perder o comando do seu espaço, devido ao crescimento da criminalidade. Temos como exemplo o Estado do Rio de Janeiro, no qual a criminalidade tomou proporções insustentáveis, pondo em risco a ordem de um Estado membro.

Segundo Silva (2008), cada ente estatal é responsável por organizar e coordenar a segurança pública regional, porém caso não seja realizada essa atividade de forma adequada, poderá ser lançada uma intervenção federal, com o objetivo de acabar com um distúrbio duradouro e violento, com grandes proporções, pondo em risco o pacto federativo. De acordo com a Folha de São Paulo (2018), em uma matéria publicada no dia 18/02/2018, muitos fatores levaram o Estado do Rio de Janeiro para uma medida tão extrema, são eles:

Não redução da criminalidade;

Crise político-financeira;

Descontinuidade de políticas de segurança pública;

Ex-Governador preso e o atual sem controle sobre da segurança pública do Estado;

Taxa de mortes violentas de 40 por 100 mil habitantes, a maior registrada desde 2009;

Registro de 688 tiroteios ou disparos de armas de fogo, média de 22 por dia;

Em 2017, morreram 134 Policiais Militares;

Redução do efetivo Policial e não contratação de policiais concursados;

Quedas na arrecadação do Estado e o preço do Petróleo está derrubando a economia.

Segundo Lobo (2018), a questão da intervenção federal no Rio de Janeiro na área da segurança pública começou a ser elaborada na terça feira de carnaval, dia 13 de fevereiro, no qual foram registrados muitos crimes graves com divulgação de imagens dessa violência; violência essa que já se tornou parte do cotidiano da população do Rio de Janeiro. A partir dessas publicidades, que mancharam mais uma vez a imagem da Cidade Maravilhosa, que durante esse período carnavalesco recebe muitos turistas, e essa situação de descontrole das autoridades policiais, iniciaram-se conversas envolvendo o Presidente da República e uma possível intervenção federal.

O Presidente da República fez algumas análises, sendo a primeira foi verificar as condições dos militares conduzirem as decisões no Estado do Rio de Janeiro. Em seguida, o Chefe do Poder Executivo se reuniu com os comandantes das três Forças Armadas para pedir o apoio de todos. Outra análise feita foi a de um estudo jurídico específicos na intervenção federal na área da segurança pública.

Dando continuidade com as tratativas do processo interventivo os Presidentes do Senado Federal e o da Câmara dos Deputados foram chamados para que seja realizada as sessões para apreciação dessa medida excepcional, preenchendo assim o rito formal. Segundo Caram et al. (2018), na madrugada de terça feira, dia 20/02/2018, a Câmara dos Deputados aprovou o decreto que autoriza a intervenção federal na 
segurança pública do Rio de janeiro, dando continuidade ao rito formal da medida. O próximo passo é que esse decreto seja encaminhado e apreciado pelo Senado Federal.

De acordo com Garcia et al. (2018), o Senado Federal na noite do dia 20/02/218, aprovou o decreto que autoriza a intervenção. Intervenção essa que foi assinada pelo Presidente da República no dia 16/02/2018, que após as apreciações das duas casas legislativas, esse decreto vai ser publicado no Diário Oficial da União.

No dia 16/02/2018, o Presidente da República, fazendo uso das atribuições, conforme o artigo 84, inciso $\mathrm{X}$ da $\mathrm{CF}$, assina o decreto 9.288, que versa sobre a intervenção federal, no qual constam pontos importantes como a duração da intervenção, indo até 31 (trinta e um) de dezembro de 2018; e a área de limitação, ou seja, somente na segurança pública. O principal objetivo desse processo interventivo é de pôr termo a grave comprometimento de segurança pública no Estado do Rio de Janeiro, ou melhor, combater esse quadro de transtorno, violento e de proporções duradouras. O respectivo decreto o Presidente da República nomeou um interventor o General do Exército Walter Souza Braga Neto. A função do interventor são aquelas previstas no artigo 145 da Constituição do Estado do Rio de Janeiro, sempre no que tange a segurança pública. O interventor fica subordinado ao Presidente da República, podendo requisitar, se achar pertinente, os recursos financeiros, tecnológicos, estruturais e humanos do Estado do Rio de Janeiro. Outro ponto muito importante do interventor que assumirá o controle operacional de todos os órgãos de segurança pública do estado, vide artigo 144 da CF e artigo 145 da Constituição do Rio de Janeiro (BRASIL, 2018).

\section{DECRETO № 9.288, DE 16 DE FEVEREIRO DE 2018}

Decreta a intervenção federal no Estado do Rio de Janeiro com o objetivo de pôr termo ao grave comprometimento da ordem pública.

O PRESIDENTE DA REPÚBLICA, no uso da atribuição que lhe confere o art. 84, caput, inciso $X$, da Constituição,

\section{DECRETA:}

Art. 1ํ Fica decretada intervenção federal no Estado do Rio de Janeiro até 31 de dezembro de 2018.

$\S 1$ 1 A intervenção de que trata o caput se limita à área de segurança pública, conforme o disposto no Capítulo III do Título V da Constituição e no Título V da Constituição do Estado do Rio de Janeiro.

$\S 2$ 2o O objetivo da intervenção é pôr termo a grave comprometimento da ordem pública no Estado do Rio de Janeiro.

Art. 2ㅇ Fica nomeado para o cargo de Interventor o General de Exército Walter Souza Braga Netto.

Parágrafo único. O cargo de Interventor é de natureza militar.

Art. 3ำ As atribuições do Interventor são aquelas previstas no art. 145 da Constituição do Estado do Rio de Janeiro necessárias às ações de segurança pública, previstas no Título V da Constituição do Estado do Rio de Janeiro.

$\S 1$ O Interventor fica subordinado ao Presidente da República e não está sujeito às normas estaduais que conflitarem com as medidas necessárias à execução da intervenção.

$\S 2$ o O Interventor poderá requisitar, se necessário, os recursos financeiros, tecnológicos, estruturais e humanos do Estado do Rio de Janeiro afetos ao objeto e necessários à consecução do objetivo da intervenção. 
§ 3o Interventor poderá requisitar a quaisquer órgãos, civis e militares, da administração pública federal, os meios necessários para consecução do objetivo da intervenção.

$\S 4$ ㅇ As atribuições previstas no art. 145 da Constituição do Estado do Rio de Janeiro que não tiverem relação direta ou indireta com a segurança pública permanecerão sob a titularidade do Governador do Estado do Rio de Janeiro.

§ 5 o O Interventor, no âmbito do Estado do Rio de Janeiro, exercerá o controle operacional de todos os órgãos estaduais de segurança pública previstos no art. 144 da Constituição e no Título V da Constituição do Estado do Rio de Janeiro.

Art. 4ㅇ Poderão ser requisitados, durante o período da intervenção, os bens, serviços e servidores afetos às áreas da Secretaria de Estado de Segurança do Estado do Rio de Janeiro, da Secretaria de Administração Penitenciária do Estado do Rio de Janeiro e do Corpo de Bombeiros Militar do Estado do Rio de Janeiro, para emprego nas ações de segurança pública determinadas pelo Interventor.

Art. 5o Este Decreto entra em vigor na data de sua publicação.

Conforme Brito et al. (2018), essa intervenção federal na segurança pública no Rio de Janeiro é a primeira desde a CF de 1988, fato esse que não pode ser confundido com outras participações da Forças Armadas para garantia da lei e da ordem, onde o Governo Federal manda tropas para ajudar nessa garantia. No caso da intervenção, é uma medida mais grave e com amplitudes maiores, na qual o Governador do ente passivo desse processo será substituído.

Segundo o Estadão (2018), em uma reportagem no dia 23 de fevereiro de 2018, o interventor General de Exército Walter Souza Braga Netto, decidiu instalar um Gabinete de intervenção federal, que ficou localizado no mesmo local do centro integrado de comando e controle. A chefia desse gabinete pertencerá ao General-de-Divisão Mauro Sinott Lopes, que se reportará diretamente ao interventor. O interventor também nomeou o General Richard Nunes como sendo o novo Secretário de Segurança.

Nesse sentido, o Portal G1, em 06 de março de 2018, traz-nos os novos chefes da Polícia Civil e da Polícia Militar, sendo eles, o Delegado Rivaldo Barbosa e o Coronel Luiz Cláudio Laviano. De acordo com o secretário Richard Nunes a escolha desses nomes tem o objetivo da valorização dos profissionais e que incremente a integração entre as polícias e as forças de segurança, fazendo assim o fortalecimento do sistema integrado de metas.

\section{CONCLUSÃO}

O Brasil adotou como a forma de Estado a Federação, na qual se objetiva uma distribuição de poderes, concedendo e mantendo certa autonomia de seus entes, que versa sobre uma auto-organização, um poder de criar suas leis, de se autoadministrar e de se autogovernar, sempre à luz da CF.

Observamos que o princípio federativo é destacado no artigo primeiro da CF, na qual menciona a indissolubilidade dos entes que compõe o pacto federativo, vedando assim o direito de secessão, no qual a regra dentro de uma Federação é que seus entes tenham autonomia, já que a intervenção é uma medida de caráter excepcional. Por isso, alguns autores mencionam em suas obras, que a intervenção federal é uma antítese de uma Federação, justamente quando o assunto é a autonomia. Para que seja mantida essa harmonia e preservado a existência federativa em caos de anormalidades, será utilizada medidas extremas, que nesse caso é a Intervenção Federal. 
É notório que a intervenção federal é algo extremo e excepcional, na qual é retirada de forma temporária a autonomia dos Estados, vindo a prevalecer a vontade da União. Para que seja decretada essa medida, vários pontos terão que ser observados. Esses requisitos são encontrados no texto Constitucional, onde foi destinado para esse assunto três artigos específicos.

Diante do que foi apresentado existem duas modalidades de decretação da intervenção: a de forma espontânea e a provocada. No caso da intervenção na segurança pública, o Presidente da República decretará de ofício, que será ouvido pelos Conselhos da República e de Defesa Nacional; essa decisão será um ato discricionário presidencial, que será formalizada através de um decreto interventivo, na qual constará a duração, a execução, a sua amplitude, no que couber nomeará um interventor. Durante esse processo será realizado um controle político, que as casas legislativas farão um juízo, dando seus pareceres, caso aprovem essa medida, a intervenção se perdurará até seu prazo ou caso antes do prazo, se o que foi combatido for resolvido. Porém, se a casa legislativa rejeitar, a intervenção deverá ser cessada imediatamente, caso não seja cessada o Presidente da República responderá criminalmente.

Ademais, observamos que para a decretação dessa medida, o texto constitucional descreve de forma taxativa as hipóteses na qual a intervenção será autorizada, como também as formalidades legais, na qual a competência é privativa do Presidente da República para decretação dessa medida.

Por fim, quando um ente recorre a um ente superior, assumindo assim sua fragilidade, sua ineficiência para combater tal situação desfavorável, é pra se pensar se um período curto como esse que foi dado para o término da intervenção federal no Rio de Janeiro até 31 de dezembro de 2018, será razoável para o restabelecimento real da ordem pública, e se é possível em meses corrigir a mazelas e as desigualdades de décadas.

\section{REFERÊNCIAS}

ALEXANDRINO, M.; PAULO, V.. Direito constitucional descomplicado. 3 ed. São Paulo: Método, 2008.

BARCHET, G..; MOTTA, S.. Curso de direito constitucional. 2 ed. Rio de Janeiro: Elsevier, 2009.

BASTOS, C. R.. Curso de direito constitucional. 21 ed. São Paulo: Saraiva, 2000

BERNARDES, J. T.; FERREIRA, O. A. V. A.. Direito Constitucional-tomo II-direito constitucional positivo. 7 ed. Bahia: JusPodivm, 2018.

BRANCO, P. G.; MENDES, G. F.. Curso de direito constitucional. 7 ed. São Paulo: Saraiva, 2012.

BRASIL. Constituição da República Federativa do Brasil de 1988. Brasília: DOU, 1988.

BRASIL. Decreto n. 9288 de 16 de fevereiro de 2018. Decreta intervenção federal no Estado do Rio de Janeiro com o objetivo de pôr termo ao grave comprometimento da ordem pública. Brasília: DOU, 2018.
BULOS, U. L.. Curso de direito constitucional. 5 ed. São Paulo: Saraiva, 2010.

COLLAÇO, G. H.; KINDERMANN, C. A.; LEONEL, V.; MOTTA, A. M.; PRUDÊNCIO, P. G.. Universidade e ciência. Palhoça: Unisul Virtual, 2013

CUNHA JÚNIOR, D.; NOVELINO, M.. Constituição federal para concursos. 6 ed. Bahia: JusPodivm, 2015.

FERREIRA FILHO, M. G.. Curso de direito constitucional. 26 ed. São Paulo: Saraiva, 1999.

GIL, A. C.. Métodos e técnicas de pesquisa social. 6 ed. São Paulo: Atlas, 2008.

LENZA, P.. Direito constitucional esquematizado. 16 ed. São Paulo: Saraiva, 2012.

LENZA. P.. Direito constitucional esquematizado. 20 ed. São Paulo: Saraiva, 2016.

LEONEL, V.; MOTTA, A. M.. Ciência e pesquisa: livro didático. 2 ed. Palhoça: Unisul Virtual, 2007. 
MASSON, N.. Manual de direito constitucional. 3 ed. Bahia: JusPodivm, 2015.

MORAES, A.. Direito constitucional. 17 ed. São Paulo: Atlas, 2005.

MORAES, A.. Direito constitucional. 33 ed. São Paulo: Atlas, 2017.

MOTTA, A. M.. O TCC e o fazer científico da elaboração à defesa pública. 2 ed. Santa Catarina: Copiart, 2015.

NOVELINO, M.. Curso de direito constitucional. $12 \mathrm{ed}$. Bahia: JusPodivm, 2017.
PINHO, R. C. R.. Da Organização do Estado, Dos Poderes, e Histórico das Constituições. 11 ed. São Paulo: Saraiva, 2011.

SILVA, J. A.. Curso de direito constitucional positivo. 7 ed. São Paulo: Malheiros, 2006.

SILVA, J. A.. Comentário contextual à constituição. 6 ed. São Paulo: Malheiros, 2008.

TEIXEIRA, M. J. H. Curso de direito constitucional. 2 ed. São Paulo: Conceito, 2011.

A CBPC - Companhia Brasileira de Produção Científica (CNPJ: 11.221.422/0001-03) detém os direitos materiais desta publicação. Os direitos referem-se à publicação do trabalho em qualquer parte do mundo, incluindo os direitos às renovações, expansões e disseminações da contribuição, bem como outros direitos subsidiários. Todos os trabalhos publicados eletronicamente poderão posteriormente ser publicados em coletâneas impressas sob coordenação da Sustenere Publishing, da Companhia Brasileira de Produção Científica e seus parceiros autorizados. Os (as) autores (as) preservam os direitos autorais, mas não têm permissão para a publicação da contribuição em outro meio, impresso ou digital, em português ou em tradução. 